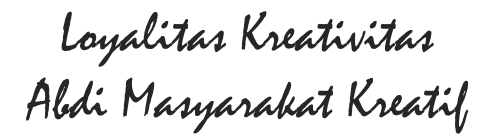

Loyalitas Kreativitas

Aldi Masyarakat Kreatif

P-ISSN 2722-2101, E-ISSN 2722-4201

Program Studi Ekonomi Manajemen Universitas Pamulang

Jurnal LOKABMAS Kreatif Vol. 01, No. 02,Juli Hal. 52-55

Email:jurnalkreatif.manajemen@gmail.com

\title{
MANAJEMEN PROFESIONAL GURU DALAM KUALITAS MENDIDIK SEBAGAI UPAYA PENINGKATAN MUTU SUMBER DAYA MANUSIA
}

\author{
Ifa Nurmasari, Hamdi Supriadi, Endah Mawarny, \\ Neneng Tita Amalya, Septi Rostika Anjani \\ Dosen Ekonomi Fakultas Ekonomi Universitas Pamulang \\ Email dosen01550@unpam.ac.id, dosen01021@unpam.ac,id, dosen01747@unpam.ac.id, \\ dosen01751@unpam.ac.id, dosen01699@unpam.ac.id
}

\begin{abstract}
ABSTRAK
Pendidikan memiliki peranan yang sangat penting dalam upaya peningkatan sumber daya manusia. Keberadaan Pendidikan harus mampu mengantisipasi perkembangan di era informasi dan globalisasi antara lain dengan cara meningkatkan sumber daya manusia dalam arti diperlukan pengembangan kepribadian seutuhnya terutama dalam pengembangan nalar yang rasional dan pemikiran yang kritis dan analitis dengan penguasaan ilmu pengetahuan dan teknologi.

Pengajar saat ini dituntut agar bisa beradaptasi dengan perubahan teknologi yang sangat cepat. Agar apa yang disampaikan pengajar dalam menyampaikan materi di kelas dapat diterima dan dapat menarik perhatian siswa, maka pengajar harus terus belajar dan beradaptasi menggunakan metode pengajaran dan teknologi yang sedang berkembang. Selain menyesuaikan metode dan menggunakan teknologi terkini, pengajar juga harus tetap meneladani bagaimana cara Rasulullah menyampaikan ilmu (berdakwah) kepada umatnya. Dengan terus memperbaiki metode belajar, mampu beradaptasi dengan perkembangan teknologi yang terus maju dan meneladani cara Rasulullah menyampaikan ilmunya, diharapkan apa yang disampaikan oleh pengajar baik mengenai materi pelajaran maupun mengenai bagaimana bersosialiasi dengan keluarga, masyarakat dapat diterima dengan baik oleh siswa. Sehingga diharapkan siswa mempunyai kemampuan tentang ilmu pengetahuan yang baik dan mempunyai akhlak yang mulia .

Tujuan dilaksanakannya kegiatan Pengabdian Kepada Masyarakat (PKM) ini diharapkan dapat menambah ilmu dan pengetahuan baru mengenai metode pengajaran, teknologi yang harus dikuasai bagi para pengajar (guru) SMA Al Manar Azhari IBS, Limo Kota Depok. Serta tidak lupa, pengajar diingatkan agar selalu meneladani, mencontoh bagaimana rasulullah saw memberikan ilmu atau berdakwah kepada umat islam. Selain itu dengan diadakan kegiatan Pengabdian Kepada Masyarakat ini juga membawa manfaat bagi dosen program studi Manajemen Universitas Pamulang karena dapat berbagi ilmu manajemen yang dimilikinya.
\end{abstract}

\section{Kata Kunci: Manajemen, Pendidikan}

\section{ABSTRAC}

Education has a very important role in efforts to increase human resources. The existence of education must be able to anticipate developments in the information age and globalization, among others, by increasing human resources in the sense of the need to develop personality wholly, especially in the development of rational reasoning and critical and analytical thinking with the mastery of science and technology.

Teachers are currently required to be able to adapt to technological changes very quickly. In order for what the instructor to convey in delivering material in class can be accepted and can attract the attention of students, the instructor must continue to learn and adapt using teaching methods and developing technologies. In addition to adjusting methods and using the latest technology, teachers must also emulate how the Prophet delivered knowledge (preaching) to his people. By continuing to 


\section{Loyalitas Kreativitas \\ Aldi Masyarakat Kreatif}

P-ISSN 2722-2101, E-ISSN 2722-4201

Program Studi Ekonomi Manajemen Universitas Pamulang Jurnal LOKABMAS Kreatif Vol. 01, No. 02,Juli Hal. 52-55

Email:jurnalkreatif.manajemen@gmail.com

improve the method of learning, being able to adapt to technological developments that continue to advance and imitate the way the Prophet conveyed his knowledge, it is hoped that what is conveyed by the teacher both about the subject matter and about how to socialize with the family, the community can be well received by students. So hopefully students have the ability about good science and have noble character.

The purpose of this Community Service (PKM) activity is expected to be able to add new knowledge and knowledge about teaching methods, technology that must be mastered by the teachers (teachers) of Al Manar Azhari IBS High School, Limo, Depok City. As well as not forgetting, teachers are reminded to always imitate, imitate how the Prophet gave knowledge or preaching to Muslims. Besides that, this Community Service activity also brings benefits to the lecturers of the Management Study Program at the University of Pamulang because they can share their management knowledge.

\section{Keywords: Management, Education}

\section{PENDAHULUAN}

Tantangan yang dihadapi siswa sekarang ini, bukan hanya godaan yang di lingkungan yang dapat oleh kasat mata, namun juga godaan yang ada di dunia maya. Dewasa ini siswa sudah terbiasa menggunakan smart phone, membaca materi pelajaran dari smart phone, berkomunikasi dengan teman menggunakan smart phone, dll. Apabila hal ini dibiarkan terus menerus akan ada dampak positif dan negatif yang didapatkan siswa tersebut. Dampak negatif dari penggunaan smart phone ini, siswa cenderung malas untuk membaca buku, karena sudah terbiasa dengan bacaan yang singkat dan to the point, dengan mencari di google. Sosialisasi siswa di dunia nyata menjadi berkurang, karena tanpa keluar rumah atau bahkan keluar kamar pun, siswa bisa berkomunikasi melalui dunia maya.

Pengajar dalam memberikan materinya sekarang ini dituntut untuk lebih professional. Pengajar juga harus bisa beradaptasi mengikuti perkembangan jaman, baik itu dalam menggunakan fasilitas dan metode mengajar yang terbaru, yang dapat diterapkan untuk 'siswa jaman now'. Selain itu pengajar juga harus tetap meneladani bagaimana metode Rasulullah dalam menyampaikan ilmu atau dakwah. Proses penyampaian materi yang dilakukan Rasulullah SAW, dapat menjadi menarik karena menggunakan metode yang tepat sesuai kadar materi yang sedang dibahas. Namun Rasulullah SAW juga tidak jarang menggunakan metode bermain untuk menghilangkan suasana tegang. Sehingga setiap pelajaran yang diberikan oleh Rasulullah SAW, dapat diterima dengan baik oleh peserta didiknya.

Sekolah / Pesantren Almanar Azhari Islamic Boarding School (AAZIBS) berlokasi di Jalan Raya Limo / Pelita No. 10 Limo, Depok, Jawa Barat 16515. Sekolah ini mempunyai Visi "Terwujudnya santri yang unggul dalam prestasi dan berakhlak mulia serta mampu bersaing dalam kehidupan global", sedangkan misinya adalah sebagai berikut :

1. Mencerdaskan para santri dengan berbagai disiplin ilmu sehingga menjadi lulusan yang berprestasi, kreatif, berakhlak mulia dan berwawasan global.

2. Menyiapkan calon pemimpin masa depan yang menguasai ilmu pengetahuan dan teknologi berlandaskan Iman dan Taqwa.

3. Menerapkan program pendidikan yang komprehensif-holistic melalui program pendidikan keagamaan, academic development, life skill (soft skill dan hard skill) berwawasan internasional.

4. Melaksanakan pembelajaran dan bimbingan secara efektif sehingga setiap santri berkembang secara optimal, sesuai dengan potensi yang dimilikinya.

5. Mengembangkan hubungan dengan lembaga-lembaga pendidikan serta institusi lain yang telah memiliki reputasi nasional dan internasional

Untuk dapat mewujudkan visi dan misi sekolah / Pesantren Almanar Azhari Islamic Boarding School (AAZIBS) tersebut, bukanlah hal yang mudah. Diperlukan semangat dan kerja keras dari seluruh elemen sekolah, baik itu guru, siswa, orang tua dan juga diperlukan fasilitas 


\section{Loyalitas Kreativitas \\ Aldi Masyarakat Kreatif}

P-ISSN 2722-2101, E-ISSN 2722-4201

Program Studi Ekonomi Manajemen Universitas Pamulang Jurnal LOKABMAS Kreatif Vol. 01, No. 02,Juli Hal. 52-55

Email:jurnalkreatif.manajemen@gmail.com penunjang yang harus dimiliki oleh sekolah. Sekolah Almanar Azhari menyediakan program pendidikan untuk SMP dan SMA. Siswa SMP dan SMA ini berusia antara 12 sampai 18 tahun. Usia tersebut termasuk dalam kelompok Milenial Generasi Z. Mereka lahir saat teknologi sedang berkembang pesat, biasanya menginginkan segala sesuatu yang serba instan, biasanya kurang ambisi untuk bisa sukses, sangat cepat beradaptasi dengan teknologi. Generasi ini punya kredibilitas tersendiri untuk membangun citra diri melalui apa yang dibagikan di sosial medianya. Cenderung malas "ribet" dengan aturan. Menjadi pengajar / guru dari 'siswa zaman now' ini tentunya memiliki tantangan yang besar dalam mengajar, membimbing siswa baik di dalam kelas saat pelajaran maupun bersosialisasi di dalam dan di luar lingkungan sekolah.

\section{RUMUSAN MASALAH}

Berdasarkan latar belakang di atas, kami dari program studi Manajemen, Universitas Pamulang (UNPAM) berinisiatif mengadakan Pengabdian Kepada Masyarakat (PKM) dengan maksud untuk sharing ilmu pengetahuan dan pengalaman mengenai manajemen menjadi guru profesional kepada guru-guru Sekolah Al Manar Azhari Islamic Boarding School (AAZIBS). Sekolah Almanar Azhari Islamic Boarding School (AAZIBS) ini merupakan sekolah yang sekaligus sebagai pesantren bagi masyarakat yang ingin memberikan pendidikan yang terbaik bagi anak-anaknya, bukan hanya ilmu akademik tetapi juga dengan ilmu Islamiknya (tafsir Alqur'an, hadits, kitab kuning, aqidah, akhlak dan lain-lain). Dimana pendidik (guru, ustad, maupun ustadjah) selain harus memberikan ilmu pengetahuannya selama 24 jam juga pastinya dihadapkan dengan berbagai karakter anak-anak sebagai peserta didik. Dimana dalam kegiatan ini akan mengambil tema mengenai "Manajemen Profesional Guru Dalam Kualitas Mendidik".

\section{TUJUAN PELAKSANAAN}

Adapun tujuan dari kegiatan pengabdian ini adalah memberikan wawasan serta arahan bagaimana bersikap profesional dalam mendidik, bagaimana kelengkapan sarana dan prasarana dapat menunjang pengajar untuk meningkatkan kualitas peserta didik menjadi lebih baik. Selain itu bagaimana lingkungan memiliki pengaruh besar pada kualitas peserta didik dan bagaimana kemajuan teknologi memiliki pengaruh besar bagi pengajar maupun peserta didik dalam meningkatkan kualitas peserta didik.

\section{TINJAUAN PUSTAKA}

Pendidikan memang telah menjadi penopang dalam meningkatkan sumber daya manusia Indonesia untuk pembangunan bangsa. Rendahnya mutu pendidikan menghambat penyediaan sumber daya manusia yang mempunyai keahlian dan keterampilan untuk memenuhi pembangunan bangsa di berbagai bidang. Penyebab rendahnya mutu pendidikan di Indonesia antara lain pada masalah efektifitas, efisiensi dan standarisasi pengajaran. Hasil survei ini menggambarkan dampak terakhir dapat dirasakan sebagai output pendidikan adalah rendahnya kompetensi sumber daya manusia Indonesia, khususnya dari lulusan Perguruan Tinggi. Pertanyaan mendasar dari fenomena ini adalah bagaimana proses pendidikan yang ada selama ini, khususnya pendidikan di Perguruan tinggi? Banyak faktor penyebab rendahnya kompetensi lulusan Perguruan Tinggi, salah satunya adalah tingkat kemampuan guru/dosen dalam proses pembelajaran, tercermin dari gaya mengajarnya. Aspek yang harus dimiliki seorang guru dalam mengajar yaitu niat, tanggung jawab, komitmen, kiat, giat dan doa untuk membawa mahasiswa mencapai tujuan pembelajaran. Bagi mahasiswa aspek yang melandasi mahasiswa untuk belajar yaitu niat, minat, kiat, giat, komitmen dan tanggung jawab dan doa.

Menurut Purwanto (2007) strategi pembelajaran yang diberikan guru siswa berdasarkan pendekatan konstruktif (constructivist -approach) lebih menekankan pada pembelajar/mahasiswa (leaner-centered). Oleh karena itu dalam proses pembelajaran ada komponen utama yaitu: 


\section{Loyalitas Kreativitas \\ Aldi Masyarakat Kreatif}

P-ISSN 2722-2101, E-ISSN 2722-4201

Program Studi Ekonomi Manajemen Universitas Pamulang Jurnal LOKABMAS Kreatif Vol. 01, No. 02,Juli Hal. 52-55

Email:jurnalkreatif.manajemen@gmail.com
1) Siswa/Mahasiswa, dengan karakteristik yang dimilikinya, baik dari dalam diri atau dari luar dirinya.

2) Tujuan, ialah apa yang diharapkan dari proses pembelajaran, merupakan seperangkat tugas atau tuntutan yang harus nampak dalam perilaku dan merupakan karakteristik kepribadian siswa.

3) Guru/dosen, ialah orang dewasa yang karena jabatannya secara formal selalu mengusahakan terciptanya situasi yang tepat sehingga memungkinkan terciptanya proses pengalaman belajar (learning experience) pada siswa, dengan mengerahkan segala sumber (learning resources) dan menggunakan strategi pembelajaran (teaching-learning strategis) yang tepat.

Proses pembelajaran dapat diartikan sebagai suatu interaksi antara siswa dengan guru dalam rangka mencapai tujuan (Abin, 1990).Dari definisi ini maka proses pembelajaran tidak hanya berlangsung satu arah (one way system) melainkan terjadi secara timbal balik (interaktif, two ways trafic system) dimana kedua pihak berperan dan berbuat secara aktif di dalam suatu kerangka berpikir (frame of reference). Tujuan interaksi belajar tersebut merupakan titik temu dan bersifat mengikat serta mengarahkan aktivitas dari kedua belah pihak. Johnson \& Jhonson (dalam Woolfolk,1988) mendefinisikan motivasi belajar adalah kecenderungan siswa untuk bekerja keras atas aktivitas belajar dalam mencapai prestasi belajarnya. W.S Winkel (1996) dalam bukunya psikologi pengajaran menyatakan motivasi belajar adalah keseluruhan daya penggerak pisikis di dalam diri siswa yang menimbulkan kegiatan belajar, menjamin kelangsungan kegiatan belajar dan memberikan arah pada kegiatan belajar itu demi mencapai suatu tujuan. Dikatakan "keseluruhan", karena pada umumnya ada beberapa motif yang bersama-sama menggerakan siswa untuk belajar.

\section{HASIL DAN PEMBAHASAN}

Kegiatan Pengabdian Kepada Masyarakat ini dilaksakan dengan 3 tahapan, yaitu : pra kegiatan, pelaksanaan kegiatan dan setelah kegiatan. Untuk pra kegiatan, dilakukan dengan melakukan peninjauan terhadap lokasi dan juga guru-guru SMA Al Manar Azhari Boarding Islamic School Limo, Depok yang akan diberikan materi. Pada saat kegiatan dilaksanakan penyampaian materi oleh dosen dan pasca kegiatan dilakukan evaluasi terhadap keseluruhan rangkaian acara pengabdian di sekolah tersebut.

\section{KESIMPULAN DAN SARAN Kesimpulan}

Berdasarkan pelaksanaan kegiatan Pengabdian Kepada Masyarakat yang dilaksanakan di SMA Al Manar Azhari Boarding Islamic School Limo, Depok pada hari Kamis sampai Sabtu, tanggal 20-22 Februari 2020 dapat diambil kesimpulan bahwa

1. Secara umum kegiatan Pengabdian Kepada Masyarakat dapat terlaksana dengan baik dan mendapat dukungan dari pihak sekolah.

2. Materi yang disampaikan oleh narasumber bermanfaat bagi guru SMA Al Manar Azhari Boarding Islamic School Limo, Depok.

\section{Saran}

Berdasarkan kegiatan yang sudah terlaksana, maka kami memberikan saran sebagai berikut :

1. Sebaiknya pendidik dapat lebih menyesuaikan diri dengan pelajar generasi milenial seperti yang dihadapi seperti sekarang ini. Penyesuaian itu dapat dalam bentuk alat sarana-prasarana yang digunakan, metode pengajaran yang digunakan maupun teknologi yang harus dikuasai.

2. Guru atau pengajar sebaiknya selalu mengikuti seminar-seminar pada bidang pendidikan sehingga dapat menambah pengetahuan yang dimilikinya.

3. Perlu dilakukan kerjasama lebih lanjut antara UNPAM dan SMA Al Manar Azhari Boarding Islamic School Limo, Depok, untuk mengetahui perkembangan hasil dari kegiatan PKM yang telah dilakukan. 


\section{Loyalitas Kreativitas \\ Aldi Masyarakat Kreatif}

P-ISSN 2722-2101, E-ISSN 2722-4201

Program Studi Ekonomi Manajemen Universitas Pamulang Jurnal LOKABMAS Kreatif Vol. 01, No. 02,Juli Hal. 52-55 Email:jurnalkreatif.manajemen@gmail.com

\section{DAFTAR PUSTAKA}

Abin, Syamsudin Makmunf, Prof.Dr.H. 1990. Psikologi Pendidikan.Bandung: IKIP

Brophy, J. 1988. Educating teachers about managing classrooms and students. Teaching and Teacher Education.

Hulasoh, E., Virby, S., \& Tilova, N. (2018). PENGENALAN KOSAKATA BAHASA INGGRIS MELALUI MEDIA STORYTELLING. Jurnal Pengabdian Dharma Laksana, 1(1), 101-110.

Qurbani, D., Oktrima, B., \& Tanjung, A. W. (2019). MENDIDIK DAN MENGAJARKAN ANAK UNTUK MENGENAL ALLAH PADA USIA DINI DENGAN METODE STORY TELLING DI TK AL-HIDAYAH PAMULANG, TANGERANG

SELATAN. Jurnal Pengabdian Dharma Laksana, 1(2), 228-239.

Pasaribu, V. L. D., Agrasadya, A., Shabrina, N., \& Krisnaldy, K. (2020). MENJADI ENTERPRENEUR MUDA YANG MEMILIKI JIWA LEADERSHIP UNTUK MENGHADAPI MASA DEPAN. Abdi Laksana, 1(1)

Pasaribu, V. L. D., Elburdah, R. P., Sudarso, E., \& Fauziah, G. (2020). PENGGUNAAN MANAJEMEN WAKTU TERHADAP PENINGKATAN PRESTASI BELAJAR DI SMP ARAISIYAH. Jurnal ABDIMAS, 1(1)

Pasaribu, V. L. D., Susanti, F., \& Hartuti, E. T. K. (2019). MEMOTIVASI SISWA DAN SISWI SMK LETRIS INDONESIA DI DALAM MENENTUKAN PILIHAN UNTUK MELANJUTKAN PENDIDIKAN ATAU BEKERJA SETELAH LULUS SEKOLAH. Jurnal Pengabdian Dharma Laksana, 1(2), 161-172.

Pasaribu, V. L. D., Oktrima, B., Prabowo, B., Arianto, N., \& Haryoko, U. B. (2020). PROGAM PENDAMPINGAN DAN PENYELENGGARAAN PENDIDIKAN ANAK PADA USIA DINI TERHADAP PRESTASI BELAJAR DILINGKUNGAN RT 020 RW 009.
KEL GIRI PENI. KEC WATES.

YOGYAKARTA. JURNAL LOKABMAS KREATIF, 1(1), 71-75.

Pasaribu, V. L. D., Sulaiman, S., Sutiman, S., Thaharudin, T., \& Purnomo, B. Y. (2020). PENGENALAN LETAK POSYANDU TERDEKAT DIKELURAHAN PISANGAN DENGAN MANAJEMEN PEMASARAN REVOLUSI 4.0 UNTUK MENINGKATKAN PENGETAHUAN MASYARAKAT LETAK DAN FUNGSI POSYANDU TERDEKAT PADA KELURAHAN PISANGAN. DEDIKASI PKM, 1(1), 105-110.

Pasaribu, V. L. D., \& Krisnaldy, K. (2019). Manajemen Risiko dan Asuransi.

Purwanto. 2007. Instrumen Penelitian Sosial dan Pendidikan, Pengembangan dan Pemanfaatan. Yogyakarta: Pustaka Pelajar

Woolfolk, A.E. 1995. Educational Psychology. Boston : Allyn and Bacon.

W.S. Winkel. 1996. Psikologi Pengajaran. Jakarta: Gramedia.

\section{DOKUMENTASI KEGIATAN}

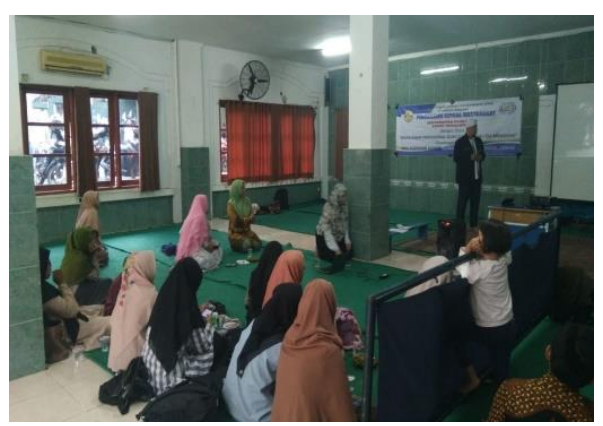

Foto pada saat penyampaian materi

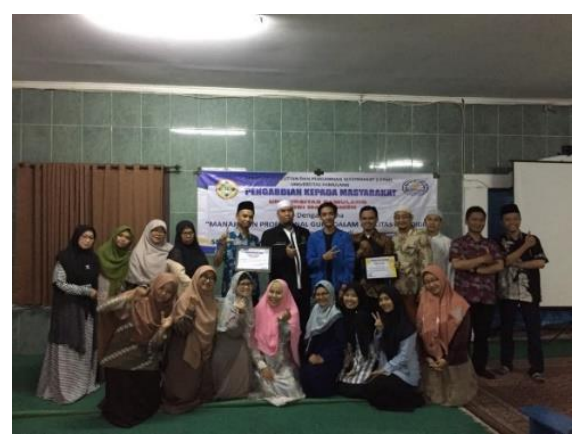

